\title{
Prevalence of Dementia among Elderly Patients attending Psychiatry OPD of Tertiary Care Hospital and its Association with Socio Demographic Variables
}

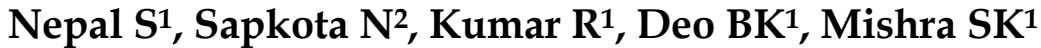

\author{
1.Assistant Professor, Department of Psychiatry, BPKIHS, Dharan, Nepal 2. Additional \\ Professor, Department of Psychiatry, BPKIHS, Dharan, Nepal
}

E-mail *Corresponding author: surajnepal51@ gmail.com

\begin{abstract}
Introduction: World is graying. With the rise in life expectancy, the elderly population is increasing. At the same time, prevalence of dementia is also increasing as ageing is the main risk factor for dementia. This study aims to find out the prevalence of dementia among old age patients and associated variables among the elderly psychiatric outpatients in a tertiary care hospital.

Material And Method: A total of 210 consecutive elderly (60 or more years) outpatients in psychiatric OPD were enrolled in a period of one year, after taking informed consent with caretakers. Mini Mental State Examination (MMSE) was done as screening tool for cognitive impairment. Diagnoses were made according to ICD-10 guidelines. Data was analysed using SPSS.

Results: Out of 210 subjects, $50.95 \%$ were female, $43.8 \%$ were of age group 60-64 years. Prevalence of dementia was 11.4\% among which Alzheimer's dementia constituted $70.8 \%$ of total cases of dementia followed by vascular dementia (25\%). Significant association of dementia was seen with age, occupation and Mini Mental State Examination (MMSE) score. Among other psychiatric comorbidities, depression (36.7\%) was found to be the commonest mental illness followed by Neurotic, stress related and somatoform disorders (13.8\%) and Alcohol dependence syndrome (12.9\%).

Conclusion: This study concludes that significant number of elderly patients attending OPD of tertiary care hospital suffers from dementia and MMSE is a reliable tool to screen dementia in the elderly patients.
\end{abstract}

Keywords: Dementia, Geriatric Patients, MMSE,

\section{INTRODUCTION}

According to the United Nation, there has been exponential growth of elderly people (60 years or over) in the world since 1960 . One out of every ten people is now elderly; by 2050, one out of five will be elderly; and by 2150, one out of three people will be elderly. The percentage is currently much higher in the more developed regions than in the less developed, but the pace of ageing in developing countries is more rapid. In 2000, there were 605 million persons more than 60 years age. In 2025, there will be more than 1 billion elderly people in the world, $75 \%$ of whom will be in developing countries and by 2050, the number will be 2 billion. ${ }^{1}$

In Nepal, there were 1.5 million geriatric population (aged above 60 ) constituting $6.5 \%$ of the total population according to 2001 national census. This population increased in 2011 to 2.7 million, accounting for $9 \%$ of total population. ${ }^{2}$

Mental illness in elderly person varies widely; conservatively estimated 25 percent have significant psychiatric symptoms. ${ }^{3}$ Certain psychiatric disorders increase in frequency with 
advancing age. With the ageing of the population, the prevalence of dementia is rapidly increasing. Age is the leading risk factor and prevalence doubles about every 5 years from about $5-8 \%$ at age 65 to 70 to $40-50 \%$ at age over 85. Alzheimer's disease accounts for about $50-70 \%$ of dementia, followed by dementia with Lewy bodies at $15-30 \%$. Vascular dementia accounts for about $5-20 \%$ and mixed cases of Alzheimer's disease plus vascular dementia about $5-20 \%$.The prevalence of Alzheimer's disease in old age ( $>60$ years) ranges from 3 to $10 \%$ and also increases with age. Among those 60 to 65 years, the prevalence is less than $1 \%$ but increases exponentially to be 24 to $33 \%$ among $>85$ years. ${ }^{4}$

Beside age, Family history of dementia, Down's syndrome, Parkinson's disease are other risk factors. Head trauma, exposure to aluminum, decreased brain reserves, low education and occupational attainment, reduced mental and physical activity in late life, use of alcohol are other possible risk factors. Hypertension, diabetes mellitus, cardiovascular diseases are risk factors implicated for vascular dementia.5,6 In view of the scanty of research in our country, we conducted this study with the aim to know the hospital based prevalence of Dementia and to study about associated variables.

\section{MATERIAL AND METHOD}

It was a cross-sectional, descriptive study over a year. Ethical clearance was taken from the Institutional Ethical Review Board of the institute. All patients over 60 years of age coming to psychiatry OPD of B. P. Koirala Institute of Health Sciences (BPKIHS) from February 2013 to January 2014 were included in the study after taking written informed consent from caretakers. Demographic profiles were noted down using a semi-structured Proforma developed by the department for this purpose. Case work up was done and Mini Mental State Examination (MMSE) was applied to all patients, unless there were any limitations in patients (like inability to speak, severe hearing impairment, violence/ agitation). The psychiatric diagnoses were based on International Classification of Diseases (ICD-10) Classification of Mental and Behavioral Disorders, Clinical descriptions and diagnostic guidelines. In cases diagnosed with Dementia,
Blessed Dementia Rating Scale was applied to assess severity. The data were recorded in Microsoft Excel 2007 and analysed using Statistical Package for the Social Sciences (SPSS) version 16.0.

\section{RESULT}

Among the 210 cases, female patients (107, $50.95 \%$ ) were slightly more than male patients. Mean age of patients was $67.29 \pm 7.302$ years. As shown in Table No 1, Twenty four of the cases $(11.4 \%)$ were diagnosed as Dementia among which seventeen had Alzheimer's dementia, six had vascular dementia and one patient had frontal lobe tumour presented with features of dementia. On the basis of Blessed Dementia Rating Scale, there were ten cases each of mild and moderate severity and four cases had severe dementia. Out of those four cases, three were of Alzheimer's type and one was dementia due to Frontal lobe tumor. Dementia was fourth common psychiatric illness among the study population; first being depression $(n=77,36.7 \%)$ followed by Neurotic, stress related and somatoform disorders (13.8\%) and Alcohol Dependence Syndrome (12.9\%).

Table 1: Distribution of patients according to types of Dementia

\begin{tabular}{|l|l|l|}
\hline Types & Frequency & $\begin{array}{l}\text { Percent } \\
(\mathbf{\%})\end{array}$ \\
\hline Alzheimer's dementia & 17 & 70.8 \\
\hline Vascular dementia & 6 & 25 \\
\hline Frontal lobe tumor & 1 & 4.2 \\
\hline Total & 24 & 100 \\
\hline $\begin{array}{l}\text { Types according to } \\
\text { severity }\end{array}$ & & \\
\hline Mild & 10 & 41.7 \\
\hline Moderate & 10 & 41.7 \\
\hline Severe & 4 & 16.6 \\
\hline Total & 24 & 100 \\
\hline
\end{tabular}

Table 2 shows socio demographic variables of patients with dementia. Out of 24 cases with dementia, most were Hindu, illiterate, unemployed or retired. Most of them were from age group 70- 79 years with equal number of males and females. All of them were from low or low middle socioeconomic status. All cases of 
dementia scored less than 25 in Mini Mental State Examination (MMSE).

Table 2: Socio- Demographic and other variables of patients with Dementia $(n=24)$

Table 3 reveals statistically significant association between occupation and dementia and also between age and dementia; shows that dementia was most common in age group 75 -

\begin{tabular}{|c|c|c|c|}
\hline Characteristics & Category & Frequency & $\begin{array}{c}\text { Percent } \\
\mathbf{( \% )}\end{array}$ \\
\hline \multirow{2}{*}{ Gender } & Female & 12 & 50 \\
& Male & 12 & 50 \\
\hline \multirow{3}{*}{ Age (years) } & $60-69$ & 8 & 33.3 \\
& $70-79$ & 11 & 45.9 \\
& $\geq 80$ & 5 & 20.8 \\
\hline \multirow{3}{*}{ Religion } & Hindu & 20 & 83.3 \\
& Kirat & 3 & 12.5 \\
Domicile & Other & 21 & 4.2 \\
\hline \multirow{3}{*}{ Education } & Urban & 3 & 12.5 \\
& Rural & 17 & 70.8 \\
\hline \multirow{2}{*}{ Occupation } & Illiterate & 4 & 16.7 \\
& Primary & 3 & 12.5 \\
\hline Socioeconomic & Farmer & 6 & 25 \\
Status & Low middle & 18 & 75 \\
\hline Physical co- & Present & 9 & 25 \\
morbidities & Absent & 15 & 75 \\
\hline \multirow{2}{*}{ MMSE score } & $\geq 25$ & 0 & 02.5 \\
& $20-24$ & 2 & 8.3 \\
& $<20$ & 22 & 91.7 \\
\hline
\end{tabular}

79 years.

\section{DISCUSSION:}

\section{Prevalence of Dementia}

Dementia was the $4^{\text {th }}$ most $c o m m o n$ mental illness among our study subjects. Our finding is in accordance to the similar study done in TUTH by Khattri JB et al. ${ }^{7}$ in 2006 which had shown prevalence of dementia as $11 \%$ of which $6 \%$ was vascular dementia and 5\% Alzheimer's dementia. Shakya $\mathrm{DR}^{8}$ had reported prevalence of dementia as $6 \%$ in same setting. Our finding is consistent with the finding of a study done by Tiwari SC et $\mathrm{al}^{9}$ in old age home in which prevalence of dementia was $11.1 \%$. Study by
Uwakwe et $\mathrm{al}^{10}$ in a hospital showed $2.8 \%$ prevalence; $9.1 \%$ prevalence was seen in the hospital based study by Ardern et al 11; 18.7\% prevalence was seen in similar hospital based study by Rockwood et al ${ }^{12}$. These differences in data might be due to the geographical variation. Our finding corresponds to the community based study carried out by kay et al ${ }^{13}$. in 1964 in northern England which showed prevalence of dementia in community as $11.3 \%$. Our finding is in accordance to a community based study by Chowdhury A et al. ${ }^{14}$ Another community based cross sectional study conducted in kerala, India in persons aged more than 65 by Shaji S, Bose $\mathrm{S}$ et al ${ }^{15}$ showed prevalence of dementia of $3.36 \%$; community based study by De Silva et al 16 in Sri Lanka showed prevalence of $4 \%$. Thus hospital prevalence was higher than community prevalence in most of the studies which are consistent to our finding.

The mean age-adjusted prevalence estimate for dementia among people aged 65 years and older living in developing countries, derived from data published within the past 10 years, was calculated to be $5.3 \%$ (95\% CI $3.9-6.5) .{ }^{17}$ This is the data for overall prevalence in community. So it shows lower prevalence of dementia in community compared to that in hospital. Our finding is not in accordance to the finding of a hospital based study by Kua Eh et al 18 who found higher prevalence of dementia $(35 \%)$. This study shows greater proportion of dementia than our study probably due to the fact that this study was carried out among geriatric patients in Singapore General Hospital, in 60 elderly patients only. So smaller sample size might be the limitation of this study. A prevalence study conducted by Karim E et al showed the overall prevalence of dementia to be $2.3 \% .{ }^{19}$ This study was the community study, so lower prevalence is the obvious finding. Other factors for low prevalence might be due to their educational and occupational status.

This shows that prevalence of dementia in community is significant. It also constitute the 
Table 3: Association of dementia with socio demographic and other variables

\begin{tabular}{|c|c|c|c|c|c|}
\hline \multirow{2}{*}{ Characteristics } & \multirow{2}{*}{ Category } & \multicolumn{2}{|c|}{ Dementia } & \multirow{2}{*}{$P$ value } & \multirow{2}{*}{ Remarks } \\
\hline & & Absent & Present $(\%)$ & & \\
\hline Gender & $\begin{array}{l}\text { Female } \\
\text { Male }\end{array}$ & $\begin{array}{l}95 \\
91\end{array}$ & $\begin{array}{l}12(11.2) \\
12(11.6)\end{array}$ & 0.921 & Not significant \\
\hline Age(years) & $\begin{array}{c}60-64 \\
65-69 \\
70-74 \\
75-79 \\
\geq 80\end{array}$ & $\begin{array}{l}87 \\
48 \\
18 \\
16 \\
17\end{array}$ & $\begin{array}{c}5(5.4) \\
3(5.9) \\
5(21.7) \\
6(27.3) \\
5(22.7)\end{array}$ & 0.004 & Significant \\
\hline Religion & $\begin{array}{l}\text { Hindu } \\
\text { Kirat } \\
\text { Other }\end{array}$ & $\begin{array}{c}131 \\
50 \\
5\end{array}$ & $\begin{array}{c}20(13.2) \\
3(5.7) \\
1(1.7)\end{array}$ & 0.281 & Not significant \\
\hline Education & $\begin{array}{c}\text { Illiterate } \\
\text { Primary } \\
\text { Secondary } \\
\text { Higher secondary } \\
\text { Bachelor } \\
\text { Masters }\end{array}$ & $\begin{array}{c}129 \\
19 \\
27 \\
1 \\
9 \\
1 \\
\end{array}$ & $\begin{array}{c}17(11.6) \\
4(17.4) \\
3(10) \\
0(0) \\
0(0) \\
0(0)\end{array}$ & 0.807 & Not significant \\
\hline Domicile & $\begin{array}{l}\text { Urban } \\
\text { Rural }\end{array}$ & $\begin{array}{c}164 \\
22\end{array}$ & $\begin{array}{c}21(11.4 \%) \\
3(12 \%)\end{array}$ & 0.924 & Not significant \\
\hline Marital Status & $\begin{array}{c}\text { Married } \\
\text { Widow/widower } \\
\text { Divorced } \\
\text { Unmarried }\end{array}$ & $\begin{array}{c}161 \\
22 \\
2 \\
1\end{array}$ & $\begin{array}{c}20(11) \\
4(15.4) \\
0(0) \\
0(0)\end{array}$ & 0.920 & Not significant \\
\hline Occupation & $\begin{array}{c}\text { Farmer } \\
\text { Unemployed/Retired } \\
\text { Businessman } \\
\text { Housewife } \\
\text { Service }\end{array}$ & $\begin{array}{c}73 \\
72 \\
12 \\
26 \\
3\end{array}$ & $\begin{array}{c}6(7.6) \\
18(20) \\
0(0) \\
0(0) \\
0(0)\end{array}$ & 0.011 & Significant \\
\hline $\begin{array}{c}\text { Socioeconomic } \\
\text { Status }\end{array}$ & $\begin{array}{c}\text { Low } \\
\text { Low middle } \\
\text { Middle } \\
\text { High }\end{array}$ & $\begin{array}{c}60 \\
106 \\
18 \\
2\end{array}$ & $\begin{array}{c}8(11.8) \\
16(13.1) \\
0(0) \\
0(0)\end{array}$ & 0.402 & Not significant \\
\hline $\begin{array}{l}\text { Physical co- } \\
\text { morbidities }\end{array}$ & $\begin{array}{l}\text { Present } \\
\text { Absent }\end{array}$ & $\begin{array}{l}93 \\
93 \\
\end{array}$ & $\begin{array}{c}9(8.8) \\
15(13.9) \\
\end{array}$ & 0.249 & Not significant \\
\hline MMSE score & $\begin{array}{c}\geq 25 \\
20-24 \\
<20 \\
\end{array}$ & $\begin{array}{c}155 \\
10 \\
1 \\
\end{array}$ & $\begin{array}{c}0(0.0) \\
2(16.7) \\
22(95.7)\end{array}$ & $<0.0001$ & Significant \\
\hline
\end{tabular}

significant portion of old age patients presenting to the hospitals. In our study also, hospital prevalence is almost double than expected community prevalence. It may be due to the fact that sample of our study is limited and it was comprised of those seeking treatment for which they came to hospital. So it is likely that dementia is more common among them than in community people.

\section{Relation between socio-demographic variables and dementia}

In our study, mean age of patients with dementia was $71.33 \pm 7.625$ years whereas those without dementia had mean age of $66.76 \pm 7.114$ years. This association was statistically significant.

Overall prevalence of dementia was $11.4 \%$; it was present in $11.2 \%$ females and $11.6 \%$ males. Similarly dementia was seen in $5.4 \%$ cases of age group 60 - 64 years, $5.9 \%$ cases of age group 65 69 years, $21.7 \%$ of age group $70-74$ years, $27.3 \%$ cases of age group 75 - 79 years and in $22.7 \%$ cases of age more than 80 years. Highest prevalence was seen in age group 75 - 79 years and this association was statistically significant. Our finding is similar to the finding of a community based study done by Evans et al which showed prevalence of dementia as $11 \%$ in 
patients aged 65 years or more and $40 \%$ in patients aged 85 years or more. ${ }^{20}$ Similar finding was seen in a hospital based study done by Bhogale GS et al in which prevalence of dementia in $60-64$ years was $11.8 \%$ and $26 \%$ among the patients aged 70 years or more. ${ }^{21}$ In a study done by Helen Gilmour et al, it was seen that $67.2 \%$ cases were female; prevalence of dementia was peak in age group 80-84 years after which prevalence was in decreasing trend. ${ }^{22}$ In our study also similar finding was seen. Prevalence of dementia was highest in $75-79$ years and lesser in more than 80 years. This may be due to a fact that older the age more the chance of dying. So due to death of subjects due to dementia or other illness obviously decreases the prevalence of dementia among the patients of older age.

Prevalence of dementia was $11.6 \%$ among illiterate patients, $17.4 \%$ in cases educated upto primary level and $10 \%$ in those educated upto secondary level. Illiteracy or low educational achievement has been shown to be a robust risk factor for dementia in earlier study. ${ }^{23}$ In a study by Alewijn Ott et al, a substantially higher prevalence of dementia was found in subjects with a low level of education. ${ }^{24}$ But in our study, association between education level and dementia was not statistically significant. This may be because of smaller study subject.

In a study in India by Chandra V et al., greater age was associated with higher prevalence of dementia but gender and literacy were not associated with it. ${ }^{25}$ Our study also showed similar result.

Association between occupation and dementia was found to be statistically significant. Twenty percent of the unemployed cases had dementia whereas farmers had $7.6 \%$ prevalence of dementia. In subjects with other occupation, dementia was not seen. This may be due to the fact that higher level of functioning is associated with lower chance of developing dementia.

It is shown that $95.7 \%$ patients with MMSE score less than 20 had dementia, $16.7 \%$ cases had dementia who had MMSE score 20 - 24 . Dementia was not seen in those cases who scored 25 or more in MMSE. Thus all the cases who had dementia scored less than 25 in MMSE. This association had high statistical significance.
It is the established fact that severe cognitive impairment can be related to dementia.

\section{CONCLUSION:}

Depression is commonest mental illness in geriatric population. Prevalence of dementia is significant in old age and it increases with increasing age. It is more common in patients with lower educational level and those with lower functionality level. With the increasing geriatric population, there is rise in population of dementia cases.

This study also concludes that Mini Mental State Examination (MMSE) is very important and reliable screening tool for dementia.

Thus, the findings of this study may open avenues for further researches in the community level, sensitize the policy makers, service providers and the general population.

\section{FUNDING SOURCE: None}

ACKNOWLEDGEMENT: The authors would like to thank all the participants and the department of psychiatry for helping in conducting this study.

\section{REFERENCES:}

1. United Nations Population Division Department of Economic and Social Affairs. Population ageing.2002.Available www.un.org/ageing/html

2. National Population and Housing census 2011 (National report). Government of Nepal, National Planning Commission Secretariat, Central Bureau of Statistics, Kathmandu, Nepal, 2012

3. Sadock J, Sadock A. Geriatric psychiatry. In: Kaplan And Sadock's Synopsis of Psychiatry 10th edition 2007: 1348-1352

4. Jeste DV, Hybels CF, Blazer DG. Geriatric Psychiatry: Overview and Epidemiology of Psychiatric Disorders. Kaplan and Sadock's Comprehensive Textbook of Psychiatry. 9th ed. Philadelphia, USA: Lippincott Williams and Wilkins; 2009: 3932-50.

5. Richards SS, Sweet RA. Dementia. Kaplan and Sadock's Comprehensive Textbook of Psychiatry. $9^{\text {th }}$ ed. Philadelphia, USA: Lippincott Williams and Wilkins;2009:1167-97

6. Gelder M, Harrison P, Cowen P. Shorter Oxford Textbook of Psychiatry. $5^{\text {th }} \mathrm{ed}$. New York: Oxford University Press; 2011. 
7. Khattri JB, Nepal MK et al. Study of depression among geriatric population in Nepal. Nepal Med Coll J. 2006 Dec; 8(4):220-3.

8. Shakya DR. Psychiatric morbidities of elderly psychiatry outpatients in a tertiary-care hospital. Journal of College of Medical Sciences Nepal 2011;7(4):1-8

9. Tiwari SC, Pandey NM, Singh I. Mental health problems among inhabitants of old age homes: A preliminary study. Indian J Psychiatry. 2012 Apr-Jun; 54(2): 144-148.

10. Uwakwe R. Psychiatric morbidity in elderly patients admitted to non psychiatric wards in a general/teaching hospital in Nigeria. International Journal of Geriatric Psychiatry 2000;15:346-56

11. Ardern M., Mayou R. et al. Cognitive impairment in the elderly medically ill: how often is it missed?. International Journal of Geriatric Psychiatry. 1993;8:929-37

12. Rockwood et al. The risk of dementia and death after delirium. Age and Ageing 1999;28:551-56

13. Kay DW, Beamish $P$ et al. Old age mental disorder in Newcastle upon Tyne. I. A study of prevalence. British Journal of psychiatry 1964; 110: $146-58$.

14. Chowdhury A, Rasania S. A Community Based Study Of Psychiatric Disorders Among The Elderly Living In Delhi. The Internet Journal of Health 2008; 7:1.

15. Shaji $S$, Bose $S$ et al. Prevalence of dementia in an urban population in Kerala, India. British Journal of Psychiatry 2005;186:136-40

16. De Silva HA, Gunatilake SB, Smith AD. Prevalence of dementia in a semi-urban population in SriLanka: report from a regional survey. Int J Geriatr Psychiatry 2003;18:711-5

17. Raj $N$ Kalaria, Gladys E Maestre et al. Alzheimer's disease and vascular dementia in developing countries: prevalence, management and risk factors. The Lancet Neurology 2008; 7(9):812-816

18. Kua Eh. Geriatric Psychiatry. Annals Academy of Medicine 1987; 16:115-117.

19. Karim E, Alam M F et al. Prevalence of Mental illness in the Community. Taj June 2006;19( 1):1019-8555.

20. Evan IA et al: Prevalence of Alzheimer's disease in a community population of older persons higher than previously reported. JAMA 1989;262:2551-2556

21. Bhogale GS et al. Geriatric patients attending general hospital psychiatry clinic. Indian J Psychiatry 1993;35(4):203-206

22. Helen Gilmour et al. People with Dementia in a Rural Community: Issues of prevalence and community care policy. Dementia 2003. http://dem.sagepub.com
23. Borenstein AR, Copenhaver CI, Mortimer JA. Early-life risk factors for Alzheimer disease. Alzheimer Dis Assoc Disord 2006; 2: 63-72

24. Alewijn Ott et al. Prevalence of Alzheimer's disease and vascular dementia: association with education. The Rotterdam study. BMJ 1995;310:970

25. Chandra $V$ et al. Prevalence of Alzheimer's disease and other dementias in rural India. Neurology 1998 october; 51(4):1000-1008 